This item was submitted to Loughborough's Institutional Repository (https://dspace.lboro.ac.uk/) by the author and is made available under the following Creative Commons Licence conditions.

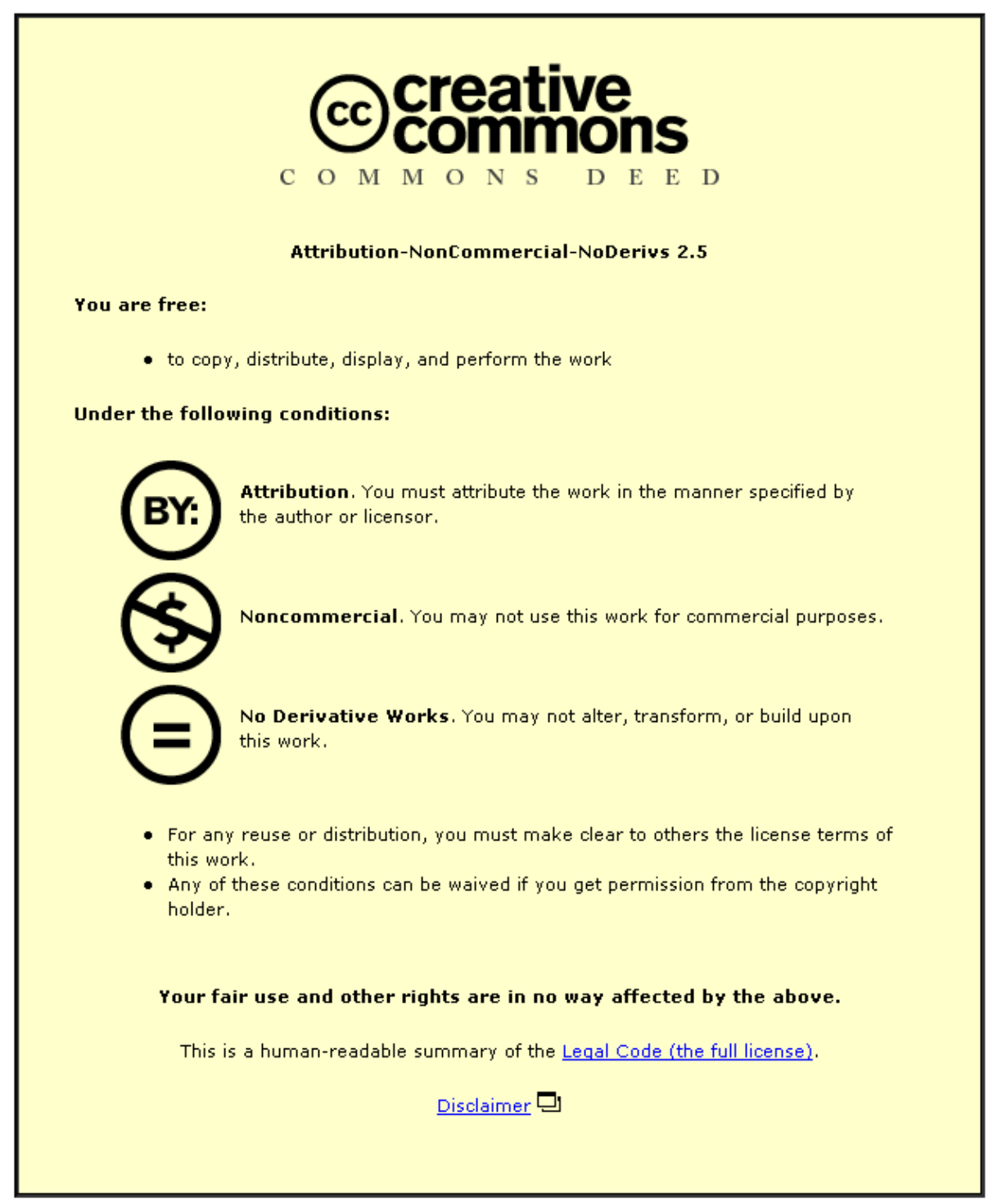

For the full text of this licence, please go to: http://creativecommons.org/licenses/by-nc-nd/2.5/ 


\title{
Lessons Learned Practices in the UK Construction Sector: Current Practice and Proposed Improvements
}

\begin{abstract}
Many construction companies in the UK engage in formal and informal lessons learned practices. However, such lessons learned are not always used to the best advantage to improve future projects; there is a disjoint in the effort spent obtaining lessons learned and their dissemination and use. This paper reports on research aimed at improving lessons learned practices in construction organisations. The paper investigates the gaps in current construction contractors' practices for recording and disseminating lessons learned. A questionnaire survey of top UK construction contractors was conducted to understand current lessons learned practices; this included what the processes were, why they were used and how they were carried out. The research also investigated lessons learned content, its usefulness and the perceived barriers to dissemination. The main findings were: (1) organisations need to collectively identify the lessons needed and target those to specific audiences; (2) the content and format of the lessons learned dictate the way in which the lessons should be captured, stored and disseminated; (3) there is a gap between the tools used for obtaining lessons learned and those found to be useful; and (4) the type of lessons required changes with the context, e.g. organisational priorities and external pressures on the construction environment. The next stage of the research will be to develop these outputs to create a roadmap for the improved dissemination and use of lessons learned in construction organisations.
\end{abstract}




\section{Introduction}

The construction industry in the UK is highly competitive with clients demanding innovative construction projects to be delivered to meet key performance targets, on-time, at reduced costs, with higher quality and fewer accidents. In response, the industry is attempting to embrace a culture of continuous improvement. The effective reuse of existing knowledge from previous projects or lessons learned could facilitate such continuous improvement resulting in better performance (and profits) with fewer mistakes, improved project team relationships and improved client relationships (Carrillo, 2004).

Gibson et al., (2007) explained how lessons learned formed a key component of companies’ knowledge. Knowledge management concerns companies’ attempts to effectively manage, store, retrieve and augment their intellectual properties (Ackerman et al., 2003). As part of this, employees should have access to the organisation's internal knowledge repositories, often referred to as "lessons learned" (Davenport et al., 1998). Lessons learned also contribute to learning organizations. The concept of learning is defined as "the intentional use of learning processes at individual, group and system level to transform the organisation on ways that are increasingly satisfying to all stakeholders” (Dixon, 1999). Lessons learned therefore form a fundamental part of learning organisations processes because it encourages collective learning of worked well or what could be improved. This aligns with the need for team learning as advocated by Senge (1990) and Pearn et al. (1997).

Although the benefits of sharing lessons learned are well known, there is little evidence to suggest that project teams take best advantage of lessons learned. Existing research points to numerous problems such as the fragmented nature of the industry that prevents effective 
feedback mechanisms to build on previous work (Fairclough, 2002; Orange et al., 1999) and the difficulties caused by the 'one of a kind' nature of construction projects (Koch, 2002). Further problems are created by the lack of organisational learning in the construction industry (Ruikar et al., 2007), and difficulties in work practices with projects being outside of mainstream organisational structures and control mechanisms (Scarbrough, 2004).

Recognising such constraints, several authors have discussed key characteristics that lessons learned programmes should include if they are to be effective. Gibson et al. (2007) suggest the following: lesson collection; lesson analysis; lesson implementation; resources; maintenance; improvement; and culture. The field of project management offers guidance for conducting lessons learned sessions (Disterer, 2002; Schindler and Eppler, 2003; Julian, 2008). Collison and Parcell (200) recommend 12 steps to capture lessons learned as follows:

1. Call the meeting;

2. Invite the right people;

3. Appoint a facilitator;

4. Revisit the objectives and deliverables of the project;

5. Revisit the project plan or process;

6. Ask "What went well?”;

7. Find out why these aspects went well, and express the learning as advice for the future;

8. Ask "What could have gone better?;"

9. Find out what the difficulties were;

10. Ensure that the participants leave the meeting with their feelings acknowledged;

11. Determine "What next?"; and

12. Record the meeting. 
In construction, several systems and tools have been proposed to capture lessons learned (Kartam, 1996; Saad and Hancher, 1998; Soibelman et al., 2003; Williams, 2004; Tan et al., 2007). Tserng et al. (2009) suggest typical questions that arise during construction processes and encourage the use of risk management approaches to extract project knowledge for effective future use. The US Construction Industry Institute (2007) has also developed a Maturity Model Matrix to assess a company's lessons learned programme and enable the identification of gaps that need to be improved.

Although guidance exists for obtaining lessons learned, there are still questions concerning the procedures for retrieving lessons learned. There are problems to be solved in handling the different file formats and storage mechanisms, alerting, retrieving and targeting lessons to those who need them most. Before measures are taken to address these problems, there is a need to understand what practices companies adopt (if at all) to capture and disseminate lessons learned. Doing so would not only give a better insight into the effectiveness of these measures, but also aid the formulation of effective strategies for disseminating lessons learned in construction organisations (Ruikar et al., 2009).

The overall aim of this research is to improve the dissemination of lessons learned in construction projects so that contractors' project teams have access to the most relevant lessons at the most appropriate time, in the most appropriate format. The key objectives of the research are to:

1. Investigate current practice for recording and disseminating lessons learned;

2. Identify potential barriers for successfully disseminating lessons learned; and 
3. Identify key factors affecting company processes to encourage a more systematic dissemination of lessons learned.

Whilst many of the tools and systems developed for lessons learned advocate the importance of sharing, many of these are passive in nature, expecting users to find relevant lessons learned, wherever they reside. This has been a major problem as busy project teams are reluctant to do this unless forced or encouraged to do so (Schindler and Eppler, 2003). Research has yet to focus on the proactive dissemination of the lessons learned in construction organisations. It is the vision that this research will develop into a larger project that will recommend a protocol for the construction industry to record and disseminate lessons learned more effectively.

This paper is a part of a broader study that was carried out in three phases. The first investigated UK contractors' current practices for recording and disseminating lessons learned. The second phase identified key factors that would encourage the institutionalisation of lessons learned, including the factors that inhibit their use. The third phase examined how current processes could be adapted to develop a process that would embed the systematic dissemination of lessons learned within an organisation's existing practices. The findings presented in this paper cover the first stage of the project, which investigated current practices for recording and dissemination lessons learned among UK contractor companies with the view to identifying the key factors involved.

\section{Project Performance and Lessons Learned}

Construction companies recognise the need to capture knowledge and thereby learn from previously completed projects; many attempt to conduct lessons learned sessions in an effort to 
improve performance. In the UK, there have been many reports urging the construction sector to improve its performance. The Construction Task Force (1998) was one of the main instigators of making the industry measure performance using Key Performance Indicators. This has had a very large take-up from the UK construction industry. Other examples include the introduction of the Highways Agency’s Capability Assessment Tool (CAT) in 2003. This has ensured suppliers can only bid for public road projects based on their CAT score. More recent publications such as Constructing Excellence’s (2009) report on "Never Waste a Good Crisis" and the UK's Cabinet Office's (2011) Government Construction Strategy have pushed contractors to become more competitive in an effort to cut project costs. This is where any learning from previous projects can play an important role.

The US Construction Industry Institute (2007) defines lessons learned as knowledge gained from experience, successful or otherwise, for improving future performance. Lessons learned can be extracted by reflecting on the experience of an activity that had taken place, helping organisations to achieve business needs and goals (Collison and Parcell 2001). Gibson et al. (2007) provide examples that include:

- A Lesson Learned that is incorporated into a work process;

- A tip to enhance future performance;

- A solution to a problem or a preventative action;

- A lesson that is incorporated into a policy or a guideline; and

- An adverse situation to avoid.

However, research has shown that learning from construction projects is fraught with difficulty and numerous problems exist (Orange et al., 1999; Carrillo, 2005; Udeaja et al., 2006). 
Fairclough (2002; p.23) noted, "with a few notable exceptions, knowledge transfer does not tend to 'ripple' out from members of project teams to their companies or other organisations”. Fairclough recounted recommendations that more time and effort need to be expended on learning lessons, and organisations need to consciously develop a learning culture. Other sectors experience similar problems. Sense (2007), investigating the industrial engineering sector, identified deliberate actions and activities need to be taken to promote learning. He highlighted "the emphasis should also be directed towards the situated (or social and practical) dimension of learning within each project context, rather than be confined to the narrow consideration of learning as only a cognitive process” (pg 411). In a multi-sector study consisting of construction, arts, healthcare and education, Bakker et al. (2011) identified five factors that affect project learning and knowledge transfer. These include: (1) Relational Embeddedness (strength of the relation between two or more organizational actors); (2) Cognitive Embedded ness (shared interpretations between parties); (3) Temporal Embeddedness (history of previous working relationship); (4) absorptive capacity and (5) motivation. This study looked at the combination of these five factors on 12 case study companies and deduced two important findings. Firstly, absorptive capacity is very important because "in order to successfully transfer project knowledge, the parent organization (project owner) should be made aware of the knowledge developed in the project, recognise its value, and be able to do something with it” (p 501). Secondly, variation in the success of project knowledge transfer cannot be explained by looking at any of the factors studied in isolation. This also relates to construction projects where these five factors are also relevant but there is no fixed combination of factors that would provide project learning. 
During a typical construction project's lifecycle, a large number of decisions are made at the early-to-mid stages that inform decisions in later phases and a large number of documents/drawings are generated. These measureable outputs are often a representation of the complex, intertwined and important 'design-construct' decisions taken by project community members (e.g. designers, contractors). Often, specialised collaborative knowledge-based systems are effective in maintaining audit trails of the drawing-document development processes. However, decisions that are intrinsic to these processes, if not adequately captured, are at a risk of loss. This negatively affects the project's collective knowledge (Ruikar et al., 2009). From a construction project's lifecycle perspective, it is important that lessons learned are captured at all key project phases so that they are available for future use. This is particularly important for larger projects with project timelines that run several years. An important aspect for any project is to develop techniques and utilise tools that facilitate capture (and sharing) of lessons learned throughout the project's lifecycle. Sometimes as project deadlines close in, these techniques are either ignored or abandoned due to the immediate need to deliver the project.

To date, much of the research and industry focus has been on capturing lessons learned from projects. However, even if lessons learned are successfully captured, there are still numerous problems to address in terms of their dissemination. Findings from previous studies (e.g. Carrillo, 2005 and Carrillo et al., 2007) indicate that even when companies have established, standard processes for obtained lessons learned, there are still questions/problems as follows:

- How to encourage staff to adhere to corporate standards for conducting and recording lessons learned?

- How to handle the different formats and storage mechanisms used? 
- How to find and retrieve the lessons learned stored in a sensible format?

- How to target the lessons learned at those project teams who need it most?

- How to alert project teams about the existence of lessons learned? and

- How to institutionalise lessons learned so that project teams systematically seek lessons learned before commencing new projects?

Several authors have highlighted the problems with dissemination. For example, Busby (1999) identified the time taken, cynicism and embarrassment at looking back, reluctance to destroy social relationships through blame and that it is it is better to learn from one's experience rather than someone else's. Van der Bij et al. (2003) stated that dissemination does not occur spontaneously, especially for those with technical backgrounds who are prone to be very individualistic. In their study, they identified three influencing factors as: (1) individual commitment; (2) organisational crises; and (3) risk-taking behaviour. They also pointed out that the most important factor is not the easiest factor to control. Wang and Noe (2010) identified issues such as fear of losing power, concern about inaccuracies, questionable value-added, criticism from others, and the social cost exposing colleagues' errors as key reasons for not sharing knowledge. More recently, Javernick-Will (2011) identified the use of knowledgesharing connections and networks in global, project-based organizations. She identified the need for organizational structures and controls to encourage collaboration and hence foster knowledge dissemination.

Lessons learned are essentially a form of knowledge creation and sharing. These questions reverberate with the known issues on the 'situated' nature of knowledge (Lave and Wenger, 1991) and the need for socialisation to transfer knowledge from tacit to explicit in a continuous 
cycle (Nonaka and Takeuchi, 1995). Nonaka et al. (2000) described the creation of the right conditions for 'dynamic knowledge creation', which include leadership. Research into the dynamic nature of learning revealed that individuals did not feel documenting learning was helpful and stressed the importance of networks (Newell and Edelman, 2008, von Zedtwitz, 2002). However, the problems that exist in the construction sector such as work practices that inhibit the development of an organisational culture to share tacit knowledge (Quintas, 2005), the 'blame culture' that may inhibit sharing of knowledge and the continuous need for continuous innovation (Egbu and Robinson, 2005) are well known.

The tools and techniques used for capturing and sharing of lessons learned are not simply information management tools as they should be 'capable' of handling the richness, the content, and context and not just the information itself (Gallupe, 2001). They have to be selected with careful thought as to how far lessons learned can be treated as information and the extent to which lessons learned are personal, based on experience and reflection, and should remain tacit (Polanyi, 1966). Learning also has a social dimension being created and shared in social groupings, within which tacit knowledge sharing occurs (Brown and Duguid, 1991). As such, as learning takes place in specific contexts, and to varying degrees 'situated' (Lave and Wenger, 1991), lessons could be ‘sticky’ and difficult to transfer or share (von Hippel, 1994). This leads to the risk of significant knowledge loss. In its latter stages, this research will therefore seek to find ways to improve this vital process. 


\section{Research Methodology}

This paper reports on the findings of a questionnaire survey of top UK construction contractors that aimed to understand current lessons learned practices. More specifically, it aimed to establish what processes are used for capturing, storing and disseminating lessons learned, the reasons why lessons learned are used and how they are carried out. The findings of this survey fed into subsequent stages of a broader study that:

- Enables contractor organisations to identify the specific needs of project teams in terms of utilising lessons learned; and

- Suggests ways in which the lessons learned dissemination methods and processes can be improved to enhance adoption and realise value.

A covering letter containing a web link to the questionnaire survey was sent to senior managers of the top 122 UK construction contractors listed in the NCE Contractors File (2010). The covering letter was addressed to Business Improvement Managers, Quality Managers, Knowledge Managers, etc. explaining the scope of the questionnaire and asking them to forward the web link to the most appropriate employees who could answer questions on the company's Lessons Learned processes. The survey attempted to gather a view from a relatively large number of respondents (Fink, 2008; Gibson and Brown, 2009). The population sample focused on top UK construction contractors, as they were considered as a group most likely to have lessons learned systems in place. This approach aligns with a complementary study to understand lessons learned by Gibson et al (2007) for US construction companies. 
The survey questionnaire was developed in two stages. First, a pilot was conducted following the advice of Saunders et al. (2006), to ensure the survey questions were relevant, easy to answer, unambiguous, and without any duplications. Second, the feedback from the pilot review led to further refinement of the questionnaire. The resulting questionnaire covered the following themes:

- Contextual data concerning the contractor company (nature of business, turnover, number of employees) and the respondent (their role and experience);

- Reasons for conducting lessons learned;

- Contents of lessons learned;

- Tools and techniques to conduct and share lessons learned; and

- Perceived barriers to lessons learned.

Some questions were designed to capture views on the degree of usefulness, ease of accessibility, timing of the lessons captured, and the teams involved in lessons learned processes. The respondents answered questions based on a five point Likert scale (e.g. $1=$ Never to $5=$ Always). There was also an option to provide free text answers to open-ended questions.

In all 41 survey responses were received from senior and middle management involved in business improvements, knowledge management, quality assurance, procurement, technical services, marketing, estimating and quantity surveying. Therefore, the views represented in this paper are of those who develop and use lessons learned. The respondent company profiles are included in Table 1. From the table it is clear that nearly three-quarters of the companies were involved in both Design and Build and traditional contracting. Also, nearly half were involved in project management and Private Finance Initiative (PFI) projects. $60 \%$ of the respondent 
companies employ in excess of 500 employees and 66\% have an annual turnover of more than £100M.

Insert Table 1 here

\section{Analysis and Research Findings}

The findings presented in this section have been arranged thematically to match the themes of the survey questionnaire, which cover reasons for conducting lessons learned, the contents of lessons learned, tools and techniques to conduct and share lessons learned, and the perceived barriers to lessons learned.

\section{Reasons for Conducting Lessons Learned}

The survey asked why lessons learned were conducted and whether there were formal procedures in place in the respondents' organisations to conduct lessons learned. Nearly three quarters (73\%) believed that there was a 'formal' procedure in place to capture and disseminate lessons learned. Respondents to this question were also asked to rank the reasons for conducting lessons learned, from a list suggested. The suggested reasons were those commonly cited in literature that drive knowledge management initiatives in companies such as: to comply with the company's knowledge and quality management procedures (Gibson et al., 2007); to avoid making mistakes and repeat successess of past projects (Caldas, 2009); to learn from similar projects in the future (Bishop, 2009); to learn lessons from consecutive stages of ongoing projects (Tan, 2006); to provide for a competitive edge over other companies and encourage innovation (Al Ghassani, 2002). 
The results suggests that lessons learned are strongly valued despite the problems known to surround such initiatives (Figure 1). Amalgamating the response from the 'strongly agreed' and 'agreed' categories, all respondents believe that the main reason for conducting lessons learned are (1) to learn for similar projects in the future and (2) and to avoid making mistakes and repeat successes. Similar reasons for conducting lessons learned had been cited in previous studies (Udjeja et al., 2007). Likewise, 95\% of the respondents also believed that lessons learned should provide a competitive edge over other companies and encourage innovation. These findings complement the argument that organisational resources provide an edge for companies as competitive advantage relies on 'what companies know and not what it owns' (Nonaka and Takeuchi, 1995 and Johannessen 2003).

Compared to the reasons cited above, respondents agreed to a lesser degree that they undertook lessons learned activities to learn for consecutive stages of ongoing projects, or to comply with the company procedures (Figure 1). Other reasons mentioned outside the suggested list were: (1) it helps to improve resource efficiency; (2) improves customer satisfaction; and (3) assists in the career development of the employees. Thus, there seems to be several primary and secondary objectives that drive lessons learned activities in organisations that need careful consideration in the capturing, storing, and dissemination. These findings contrast with previous studies such as those by Gibson et al. (2007) that had found that employees believed that lessons learned are done as a result of management interest or that clients had motivated some contractors to start lessons learned programmes by requesting it on projects.

Insert Figure 1 here 


\section{Types of Lessons Learned}

If avoiding making mistakes is one of the main reasons for doing lessons learned, it is important to recognise which types of lessons learned may be used in a typical project life cycle. As experiential learning throughout a construction project can cover a very wide range of topics, the survey tried to establish the type of lessons learned that people find useful to be extracted from projects. The survey suggested a list of topics that could be captured during design, procurement, delivery and handover stages (Table 2). The respondents ranked whether these were currently included, or repondents would want to be included. As seen in Table 2, respondents described up to five areas of knowledge considered useful and further described the informally shared knowledge between colleagues. Overall, the responses suggest a strong desire to learn lessons for every stage of a project lifecycle.

Insert Table 2 here

Design: The main issues included in lessons learned were planning (72\%), method of work (64\%), and estimating (52\%). There is a strong desire for innovation to be part of lessons learned with $48 \%$ citing this as 'currently included' and a similar percentage wanting 'to be included'. 'Innovation' was a frequently cited word in the descriptions, but not elaborated perhaps as a limitation of the survey.

Procurement and Delivery: Sub-contractor procurement is selected by $64 \%$ while material procurement was identified by a half of the respondents. The results suggest that the priorities of the general construction climate in the UK play an important part in what organisations should address when generating useful lessons learned. For example, the split between 'currently included' and wanting 'to be included' lessons generated during delivery of projects are: Health 
and Safety and Environmental Issues strongly desired with $80 \%$ and 19\%, and $72 \%$ and 20\% respectively. Site processes were less desired with a split of 52\% and 50\%.

Handover: Issues with snagging (64\%) are part of lessons learned, while another 34\%, indicated a desire for lessons learned to address this area. The lessons learned that drawings can generate need further careful consideration. 50\% mentioned that As-built drawings were part of lessons learned, but only another $14 \%$ indicated a desire to include this issue. In contrast, Drawings, models and sketches are 'currently included' in about $25 \%$ but $46 \%$ wanted 'to be included'. The indication to extract learning from drawings needs further investigation to precisely understand the user's requirements.

Work Practices: Issues relating to work practices within one’s own organisation also make an important area of knowledge in lessons learned. About a half considered knowledge about interaction with clients, design team and team work issues within the organisation were 'currently included' with at least another 35\% wanting 'to be included'.

\section{Tools and Techniques Used For Lessons Learned}

The format and content, and the selection of appropriate tools and techniques for capturing, storing and disseminating lessons learned depend upon the type of lessons required. However, the practices that are used in reality are a result of what the organisations consider as bringing perceived benefits. Several techniques to capture (e.g. knowledge bases, post project reviews, discussion forums) and share (e.g. Web publishing, communities of practice, intranet/ extranet, instant messaging, video conferencing, face-to-face interactions, seminars, mentoring and training) lessons learned have been discussed in detail in previous studies (Ruikar et al., 2007). 
This survey explored the methods that are used by companies to learn from past projects and, having used such practices, whether they were considered effective.

Insert Table 3 here

The most commonly used practices for lessons learned activities include both explicit and tacit methods such as post project reviews (68\%), company intranet/ extranet (64\%), and face-to-face meetings (62\%) (Table 3). Apart from these three tools and techniques, the rest are not commonly used. Telephone conversations were cited by $38 \%$ which is the next most commonly used. Other suggested practices of brainstorming, knowledge repositories, project files and minutes of meetings, technical forums and communities of practice not being very popular with less than $33 \%$ citing as being commonly used. In addition to the listed practices, the respondents identified methods such as company Wikis, appraisals, tender approval meetings, customer satisfaction surveys, performance reviews, subcontract reviews, personal development reviews and training workshops as other commonly used methods.

However, the most informative practices rank differently with communities of practice (56\%), brainstorming sessions (54\%), and knowledge repositories (53\%) being the most informative, followed by post project reviews (52\%) and face-to-face meetings (52\%) and to a lesser extent technical forums (42\%). Figure 2 groups the most commonly used practices (above and below 50\%) against most informative practices (above and below 50\%). Face-to-face meeting and post project reviews were commonly used and most informative. Telephone conversations, video conferencing, skills and expertise database, technical forums, minutes of meetings and project files were of low usage and not informative as tools and techniques for lessons learned. 
Company intranets were commonly used, but were considered not to be informative. Brainstorming and communities of practice that enables tacit lessons learned and knowledge repositories that enables explicit lessons learned were not commonly used tools and techniques, but considered most informative. The disparity in the techniques used and those found to be informative suggests that tools and techniques may need to be scrutinised periodically against the objectives and types of knowledge sought if they are to be more effective.

Insert Figure 2 here

Respondents further identifed measures used to prevent mistakes and repeat success of past projects. These were:

- Communities of practice, which were either electronic or in the nature of conferences;

- $\quad$ Dedicated defects avoidance teams;

- Performance reviews;

- Feedback into estimating;

- Management of expertise in the project teams;

- Analysis of failure and success;

- Using lessons learned at the start of projects; and

- Improving project close outs.

At this stage of the research it is inconclusive which of the suggestions may be most effective and further research is necessary, especially from the point of the user to understand the specifics of the problem before any solution can be proposed. 


\section{Project Stages When Lessons Are Captured}

If learning is to be made available in a useful way, the lessons learned captured and used in the typical project life cycle need to be better understood. The survey attempted to understand the different stages at which lessons learned are conducted in a typical project life cycle. The results suggest a difference in timing at which formal and informal lessons learned activities take place. Figure 3 shows most informal lessons learned activities seem to happen during the early stages of a project. During the bidding stages several informal lessons learned activities take place. The respondents described these as learning from past projects by either referring to documents or by consulting colleagues to inform the bidding process. In fact, it is during the bidding stages that most lessons learned activities happen with the highest number of respondents (about 50\%) saying that this happens informally. In comparison, about $42 \%$ said that formal lessons learned activities happen immediately after completion of a project. It is also noteworthy that during construction around $25 \%$ said that lessons learned takes place formally, informally and both formally and informally, thus indicating that in this stage lessons learned in both forms is likely to happen.

Thus, to enable the aims of conducting lessons learned to avoid making mistakes and learn for similar situations, the lessons learned would have to take into account the nature of sharing that happens informally in early stages and more formally at later stages. Therefore, different types of knowledge, as highlighted in the preceding section, may be needed in different formats depending on the manner of sharing during the project life cycle. Moreover, , the tools and techniques used will have to depend on whether lessons learned activities are conducted formally or informally. 
Insert Figure 3 here

\section{Participants At Lessons Learned Sessions}

Gibson et al. (2007) suggest that a successful lessons learned programme would delegate and differentiate the roles with responsibility given for various stages. There needs to be leadership and vision from senior management, with delegated responsibility for generating lessons learned (capture and analysis) and also for the dissemination of lessons learned. The respondents ranked the likelihood of different roles in the company in participating in lessons learned activities. The answers of 'always', sometimes', ‘don’t know, 'occasionally and 'never' were ranked in a Likert scale of 5-1. Scores greater than 3 suggest the likelihood of participation and scores below 3 suggest unlikely to participate.

The most common participants of lessons learned activity are project managers, contract managers and quantity surveyors. Other members closely associated with the project team such as commercial managers, design managers, health and safety managers and regional managers were the next group of people likely to be involved. Those members considered as external to the core project team such as business improvement managers, sub-contractor representatives and client's representatives were less likely to participate in lessons learned activity. There seem to be an apparent division between the project team and others in the involvement of lessons learned. This issue needs further investigation to understand whether lessons learned are considered as 'insider' experience of particular groups and if so, how this may affect capturing, sharing and accessibility of lessons learned across teams. Business improvement managers are known to be closely associated with lessons learned as developers of infrastructure for enabling 
learning, but it is noteworthy that their disassociation in the implementation stages has been highlighted.

Insert Table 4 here

\section{Perceived Barriers to Lessons Learned}

Several authors have discussed barriers to learning and sharing. For example, Carrillo (2004) suggests that the lack of senior level support and vision is a common occurrence attributing to failures in learning in construction companies. Al Ghassani (2003) argues that the lack of an organisational culture for learning and willingness to share poses a barrier to knowledge sharing and further argues that people like rewards but that these have to be carefully managed for desired outcomes. Bishop (2009) recommends that developing technical infrastructure such as including intranet, internet and repositories, and outlets to such as (teams, relationships and networks, brainstorming, communities of practice) could overcome obstacles for the successful sharing of knowledge.

In order to improve usage of lessons learned, the survey attempted to capture the accessibility to lessons learned because of known problems that inhibit sharing. Depending on the manner in which lessons learned are presented, they can create disputes with individuals or departments being blamed for errors, they may carry commercially sensitive information which companies do not want to share openly or could give rise to legal claims if errors in construction are openly discussed (Carrillo et al., 2007, Gibson et al., 2007). 
These suggested barriers in literature were presented as answer choices in the survey. In general, respondents thought that none of the reasons suggested were barriers for either implementing or improving a lessons learned strategy in their companies. Figure 4 shows the lack of incentives was the highest scoring barrier followed by lack of a learning culture. In fact, very few respondents strongly agreed on any reason with a clear split of opinions about barriers suggested. There was disagreement that the lack of a learning culture was a reason, or being unaware of value added or the lack of technical infrastructure or outlets to share lessons learned. The respondents were given the choice to provide other barriers. The issues noted were: (1) pressure of time to devote to lessons learned; (2) the reluctance to share problems; and (3) that lessons learned exercises are too generic to be of value. This split in opinion and other reasons mentioned earlier in this paper brings us to question whether the underlying problem rests in other issues. The earlier findings of this paper highlighted issues about the content of available lessons learned (Table 2), their usefulness and whether tools and techniques used are geared to the nature of learning sought (Table 3 and Figure 2).

Insert Figure 4 here

Taking another perspective, over $50 \%$ of respondents were neutral or disagreed with the list of barriers provided. The greatest disagreements were about the lack of outlets to share lessons learned and obtaining senior management support.

The respondents were further asked to select the level of access to lessons learned from a list of five (Table 5). While 66.7\% stated that lessons learned are open to all, the remaining $33.3 \%$ stated different types of restrictions. Such restrictions may indicate some of the barriers that are 
to be overcome if more learning through experience is to be encouraged through lessons learned programmes.

Insert Table 5 here

The respondents also indicated their own views about how sharing of lessons learned could be improved as follows:

- Raising awareness of the existing lessons learned and effective distribution;

- Simplifying and coordinating the available systems;

- Gearing lessons learned to the roles of individuals;

- Improving the sharing culture within the industry;

- Incentives of different kinds;

- Incorporating lessons learned into operating procedures;

- Improving feedback mechnisms; and

- Creating champions for lessons learned.

These ideas will need to assessed in more detail in the next stage of work when a strategy for improvement is proposed.

\section{Towards Improving Current Practices}

This paper investigated the current practices for recording and disseminating lessons learned, identified potential barriers for disseminating lessons learned, and identified key factors affecting 
company processes to encourage a more systematic dissemination of lessons learned. Some of the key themes that the results suggested are as follows.

\section{Prioritising and Sharing Objectives}

The reasons for conducting lessons learned programmes are varied and range from project-based objectives that require specific types of knowledge to facilitate individual roles within projects to corporate-based objectives such as business improvement (Figure 1). Liebowitz and Megbolugbe (2003) support this by highlighting the need for both company directors and professionals to identify the areas of knwoledge to be captured. Therefore, if programmes are to be effective, organisations will have to develop and structure their programmes prioritising the organisation's objectives (Carrillo, 2005 and Gibson et al., 2007). For example, if learning to make fewer mistakes and repeat success are the primary intention as shown in Figure 1, lessons learned would need to capture precise problems and describe successful and unsuccessful solutions in relation to those problems (Weiser and Morrison, 1998).

As revealed in the findings, lessons learned programme designers and project users seem to be at different ends of the spectrum. The respondents who design and drive lessons learned do not participate in the lessons learned sessions to understand what is required, and therefore, how to amend and improve the feedback loops. Moreover, success will also largely depend on meeting the needs of the users. Thus, those who drive it and use it would need to share the same objectives. 


\section{Content and Format of Lessons Learned}

Such sharing of objectives would enable the format and content of lessons learned captured to be geared to the nature of use. O’Dell and Grayson (1998) pointed out the need to use a framework such as the APQC's Process Classification Framework to make project information more readily accessible. The findings suggested that sharing of lessons learned mostly happen informally at the bidding stages of a project (see Figure 3). If this is to be faciliated through a lessons learned programme, the nature of lessons learned to be generated, formats for easy sharing and therefore the selection of tools and techniques would be influencing factors in the learning loop. Similarly, formal lessons learned activities mostly take place immediately after the completion of the project (Figure 3). Given the popularity of Post Project Reviews and the Intranet, these tools and techniques should be recommended for capturing and sharing at this stage.

As most of the lessons learned currently captured and shared in Post Project Reviews and intranets are descriptions of events and remedial action, the format of lessons learned would need to improve to extract learning. Companies may need to address the questions of 'Do lessons learned address objectives at project level and the corporate level?' 'Do the tools and techniques used facilitate the learning required?' and 'Do the processes of capturing, storing, retrieving and accessing lessons learned address the problems they are designed to deal with?'

\section{Gap Between Usage and Usefulness of Tools and Techniques}

The range of tools and techniques available for managing knowledge has been in the public domain for over a decade (see for example Ruggles, 1997 and Tiwana, 2000). The results suggests that tacit and explicit tools and techniques cited by Ruikar (2007) are still used for 
recording and disseminating lessons learned with varying degrees of popularity. Post project reviews, face-to-face meetings and company intranets are popular but other tools and techinques show a remarkably low degree of usage (less than 32\%) for capturing and disseminating lessons learned. In fact, tacit techniques such as brainstorming, telephone conversations and explict techniques such as minutes of meetings, knowledge repositories and project files are used by less than a third, while technical forums, communities of practice, knowledge repositories are used by less than a quarter. Despite what is currently used, results suggest a desire for tacit techniques such as brainstorming, technical forums, and communities of practice and for explicit tools such as knowledge repositories and skills and exptertise base. This gap between the usage and usefulness of tools and techniques would need to be further investigated in relation to the format, content and nature of sharing of lessons learned (Table 3). For example, brainstorming was thought to be useful although not used as some of the other techniques (Figure 2). Although this survey cannot comment on how brainstorming sessions are conducted in different companies, typically brainstorming requires a group of individuals to focus on a problem and intentionally propose as many deliberately unusual solutions as possible through pushing the ideas as far as possible. Only when the brainstorming session is over are the ideas evaluated (Tsui, 2002). As such, it raises a question about what users may consider as useful lessons learned. Does this indicate the nature of learning required to address users' need in busy environment of construction? Is there a gap in the process for a Lesson Analysis phase as Gibson et.al. (2007) suggest where information is extracted from previous projects to create ideas applicable to other contexts and situations? Perhaps, as suggested, an analysis phase for lessons learned activities, which does not happen in the UK at present, might be needed and therefore the capture and storage of lessons learned, would need to facilitate such analysis. 


\section{Publicising Lessons Learned}

Quintas et al. (1997) pointed out the importance of ensuring knowledge is distributed to those people in the organization who need it. This proposal covers two main strands. Firstly, access to the lessons learned recorded and secondly, how those lessons learned are publicised. Table 5 showed more than a third of respondents cited certain restrictions in accessing lessons learned. Thus, any improvement would have to consider the extent to which lessons learned need to be transferred between project teams to foster corporate learning and how best this should be done. This would have to take cognisance of any confidentiality issues that need to be kept within team boundaries only. Secondly, respondents were helpful in proposing ways in which the awareness of existing lessons learned could be improved. The analogy here is that lessons learned could be considered in need of a "public relations makeover". In other words, responsibility must be allocated to publicising the lessons learned and ensuring that when employees attempt to retrieve those lessons learned, it is easy to do, relevant and useful.

\section{Generating Dynamic Lessons Learned}

The priorities in knowledge areas currently required were for issues relating to construction practices in:

- Health and Safety;

- Environmental Issues; and

- Innovation. 
These reflect the current climate of the practice and UK government priorities, which may change from time to time (Table 2). Lessons learned therefore need mechanisms to recognise that lessons that users may find useful are not static but are dynamic with the priorities of the sector in general. These findings were used to inform the conclusions developed in the next section.

\section{Conclusions}

This research set out to understand the reasons for conducting lessons learned, contents of lessons learned, the tools and techniques used to conduct and share lessons learned and the perceived barriers to lessons learned. This research revealed that lessons learned are primarily conducted to:

- Learn from similar past projects to avoid repeating mistakes;

- Ensure that past successes are replicated in future projects;

- Gain a competitive edge over other companies;

- Avoid corporate 'brain drain', a problem compounded by redundancies and retirement; and

- Encourage innovation.

There is, therefore, a need for a sustained effort by the owners of lessons learned processes to identify the priorities within their company where the effects of knowledge loss are most felt. This prioritisation of needs should influence the decisions on the most suitable tools and 
techniques to capture learning and facilitate sharing. The content of what is to be captured and shared also follows on from these needs.

The format and content of the lessons learned depend on the nature of sharing that clearly differs along the project lifecycle. For example, the study found that more informal lessons learned are shared during the early stages of a project, whereas more formal activities to capture and share seem to happen during the final stages.

Tools and techniques to capture and store lessons learned should enable different forms of sharing at these various stages. The disparity revealed in the usage and usefulness of tool and techniques could be linked to the insensitivity of tools and techniques to these differences. Company processes need to build in feedback loops to periodically assess their effectiveness, recognising that needs change and therefore, the type of lessons learned needed.

Accessibility and publicity of lessons learned need to be resolved, if company objectives in investing in lessons learned are to be realised. One important finding of this research is that vast quantities of project data are being collected and stored in company repositories. This is primarily driven by the company's knowledge management strategy, but there seems to be little done to incentivise staff to exploit these repositories for a host of reasons. This indicates that while the companies have taken positive steps to initiate 'lessons learned' capture, the benefits of 'learning' are not realised. More needs to be done to not only ensure that the lessons are accessible to those to need them, when they need them; but also to ensure that the validity and integrity of the lessons learned are continually monitored. 
In the current unstable economic climate and growing global competition, it is recognised that only the fit can survive in the long-term. Long-term survival is largely dependent on a company's ability to 'ride the tide' by generating and exploiting innovative ideas and bringing to market those products, services and management approaches that differentiate it from its rivals. While most companies may dismiss this statement as something of a cliché, only a few take proactive measures to ensure that every employee has both, the means and the will to help the organisation realise its knowledge potential. Unlike replicable business models that focus on cost, quality and time-based competitiveness, a knowledge-based approach is an unique aspect of competitiveness that cannot be easily replicated and hence of value for long-term survival. Recognising this is the first step towards realising the value.

A limitation of this research is that the findings represented the views of those based in companies' head offices that drive lessons learned and therefore may not fully represent the views of project teams. As well as building corporate infrastructure, the needs of key users in the project teams should be understood. The next stage of this research will investigate these questions to propose how lessons learned methods and processes can be adapted to encourage systematic dissemination of lessons learned in order to increase their adoption. 


\section{References}

Ackerman, M., Pipek, V. and Wulf, V 2003) Sharing expertise: Beyond knowledge management, MIT Press, Cambridge, Mass.

Al-Ghassani, A.M. (2002) Literature review on KM tools. Technical Report, July 2002, Department of Civil and Building Engineering, Loughborough University, UK.

Al-Ghassani, A.M. (2003) Improving the structural design process: A knowledge management approach. Department of Civil and Building Engineering, Loughborough University, UK.

Bakker, R., Cambré, B., Korlaar, L. and Raab, J. (2011) Managing the project learning paradox: A set-theoretic approach toward project knowledge transfer. International Journal of Project Management, 29(5), 494-503.

Bishop, J. (2009) Managing technical knowledge to enhance organisational best practice. Department of Civil and Building Engineering, Loughborough University, UK.

Cabinet Office (2011) Government Construction Strategy. The Cabinet Office. London.

Caldas, C.H., Gibson, G.E. Jr, Weerasooriya, R, and. Yohe, A.M. (2009) Identification of Effective Management Practices and Technologies for Lessons Learned Programs in the Construction Industry. Journal of Construction Engineering and Management, 135(6), 531539.

Carrillo, P.M. (2004) Managing Knowledge: Lessons From the Oil and Gas Sector. Construction Management and Economics, 22(6), 631-642.

Carrillo, P.M. (2005) Lessons Learned Practices in the Engineering, Procurement and Construction Sector. Journal of Engineering, Construction and Architectural Management, 12(3), 236-250. 
Carrillo, P.M., Oluikpe, P., Harding, J.A., and Anumba, C.J. (2007) Extracting Knowledge form Post Project Reviews - Work Package 2. Loughborough University, Internal Report, December, 2007.

Collison, C. and Parcell, G. (2001) Learning to Fly. Capstone Publishing Limited, Oxford. Constructing Excellence (2009) Never Waste a Good Crisis. Constructing Excellence, London. Construction Industry Institute (2007) Effective Management Practices and Technologies for Lessons Learned Programs. Research Summary 230-1, Construction Industry Institute, Austin, Texas.

Construction Task Force (1998) Rethinking Construction, HMSO, London.

Creswell, J. (2009) Research design : qualitative, quantitative, and mixed methods approaches, Sage Publications, California.

Davenport, T., De Long, D., and Beers, M., (1998) Successful Knowledge Management Projects. Sloan Management Review, 39(2), 43-57

DBA (2003) Learning from Experience, David Bartholomew Associates, Cheltenham.

Disterer, G. (2002) Management of Project Knowledge and Experiences. Journal of Knowledge Management, 6(5), 512-520.

Dixon, N. (1999) The Organizational Learning Cycle: How We can Learn Collectively. McGraw-Hill, Aldershot.

Egbu C O and Robinson H S (2005) Construction as a Knowledge-Based Industry, in Anumba C J, Egbu C O and Carrillo P M (eds.), Knowledge Management in Construction, Blackwell Publishing, Oxford.

Fairclough, J. (2002) Rethinking construction innovation and research, a review of government R\&D policies and practices, Department of Trade and Industry, London. 
Fellows, R. and Liu, A. (2003 Research Methods for Construction, Blackwell Publishing, Oxford.

Fink, A. (2008) Practicing Research: Discovering Evidence that Matters, Sage Publications, London.

Gibson, G.E., Caldas, C.H., Yohe, A.M. and Weerasooriya, R. (2007) An Analysis of Lessons Learned Programs in the Construction Industry, $2^{\text {nd }}$ edition, Construction Industry Institute, Texas.

Gibson, W. and Brown, A. (2009) Working with Qualitative Data, Sage Publications, London.

Johannessen, J. Olsen, B. (2003) Knowledge management and sustainable competitive advantages: The impact of dynamic contextual training, International Journal of Information Management, 23( 4), 277-289.

Julian, J. (2008) How Project Management Office Leaders Facilitate Cross-Project Learning and Continuous Improvement. Project Management Journal, 39(3), 43-58.

Kartam, N. A. (1996) Making Effective Use of Construction Lessons Learned in Project Life Cycle. Journal of Construction Engineering and Management, 122(1), 14-21.

Koch, C. (2002) The emergence of second generation knowledge management in engineering consulting, in International Council for Research and Innovation in Building and Construction CIB W78 conference, Denmark, 12-14 June, 1-8.

Lave, J. and Wenger, E. (1991) Situated Learning: Legitimate Peripheral Participation, Cambridge University Press, Cambridge.

Liebowitz, J. and Megbolugbe, I. (2003) A set of frameworks to aid the project manager in conceptualizing and implementing knowledge management initiatives. International Journal of Project Management, 21(3), 189-198. 
New Civil Engineer (2010) Contractor’s File 2010, New Civil Engineer, London.

Newell, S. and Edelman, F.E. (2008) Developing a dynamic project learning and cross-project learning capability: synthesizing two perspectives. Information Systems, 18(6), 567-591.

Nonaka, I. and Takeuchi, H. (1995) The Knowledge Creating Company: How Japanese Companies Create the Dynamics of Innovation, Oxford University Press, New York.

Nonaka, I., Toyama, R. and Konno, N. (2000) SECI, Ba and leadership: A Unified Model of Dynamic Knowledge Creation. Long Range Planning, 33(1), 5 - 34.

O’Dell, C. and Grayson, C.J. (1998) If Only We Knew What We Knew: Identiifcation and Transfer of Internal Best Practices. California Management Review, 40(3), 154-174

Orange, G., Burke, A. and Cushman, M., (1999) An approach to support reflection and organisational learning within the UK construction industry in BITWorld'99 conference, Cape Town, SA, 30 June -2 July.

Pearn, M., Roderick, C. and Mulrooney, C. (1997). Learning Organization Practice. Mc GrawHill, London.

Polyani, M. (1966) The Tacit Dimension, Doubleday \& Company, New York.

Quintas, P. (2005) The Nature and Dimensions of Knowledge Management in Knowledge Management in Construction, Blackwell Publishing, Oxford.

Quintas, P. Lefrere and Jones, G. (1997) Knowledge Management: A Strategic Agenda. Long Range Planning, 30(3), 385-391.

Ruggles, R. (1997) Knowledge Management Tools. Butterworth-Heineman, Newton.

Ruikar, K. Anumba, C. J. and Egbu, C. (2007) Integrated use of technologies and techniques for construction knowledge management. Knowledge Management Research \& Practice, 5(2), $97-311$. 
Ruikar, K., Koskela, L. and Sexton, M.G., (2009) Communities of Practice in Construction Case Study Organizations: Questions \& Insights, Construction Innovation, 9(4), 434-448.

Saad I.M.H. and Hancher, D.E. (1998) Multimedia for Construction Project Management:

Project Navigator. Journal of Construction Engineering and Management, 124 (1), 82-99.

Saunders, M., Lewis, P. and Thornhill, A. (2006) Research Methods for Business Students, Financial Times Prentice Hall, Harlow.

Scarbrough H, Swan J, Laurent S, Bresnen M, Edelman L and Schindler S, M. and Eppler, M. J. (2003) Harvesting project knowledge: a review of project learning methods and success factors. International Journal of Project Management, 21(3), 219-228.

Schindler, M. and Eppler, M.J. (2003) Harvesting project knowledge: a review of project learning methods and success factors. International Journal of Project Management, 21(3), 219-228.

Senge, P. (1990) The Fifth Discipline - the Art of Practice of the Learning Organization. Doubleday, New York.

Sense, A. (2007) Structuring the project environment for learning. International Journal of Project Management, 25(4), 405-412.

Soibelman, L., Liu, L.Y, Kirby, J.G., East, E.W., Caldas, C.H. and Lin, K.Y (2003) Design Review Checking System with Corporate Lessons Learned. Journal of Construction Engineering and Management, 129 (5), 475-484.

Tan, H.C., Carrillo, P.M., Anumba, C.J. and Bouchlaghem, N.M. (2007) Development of a methodology for live Capture and Reuse of Project Knowledge in Construction. Journal of Management in Engineering, 23(1), 16-26.

Tiwana, A. (2000) The Knolwledge Management Toolkit. Prentice-Hall, New Jersey. 
Tserng, H.P., Lin S.Y.L., Dzeng, R.J., Wou, B., Chen, W.Y. (2009) A Study of ontology-based risk management framework in construction projects through project life cycle. Automation in Construction, 18(7), 994-1008.

Tsui, E. (2002) Technologies for personal and peer-to-peer knowledge management", CSC Leading Edge Forum Technology Grant Report, Available at http://go.webassistant.com/wa/upload/users/u1000057/p2p_km.pdf. Last $\quad$ viewed $19^{\text {th }}$ September 2011.

Udeaja, C., Kamara, J.M., Carrillo, P.M., Anumba, C.J., Bouchlaghem, N.M. and Tan, H.C. (2006) Live Capture and Reuse of Construction Project Knowledge: Capri.Net Approach, International Conference on Construction Culture, Innovation and Management (CCIM), M. Dulaimi (ed.), Dubai, 26-29 November, 813-823.

Van Der Bij, H.,Song, X. andWeggeman, M. (2003) An Empirical Investigation into the Antecedents of Knowledge Dissemination at the Strategic Business Unit Level. Journal of Product Innovation Management, 20(2), 163-179

Von Hippel, E. (1994) "Sticky Information" and the Locus of Problem Solving: Implications for Innovation. Management Science, 40(4), 429-439.

Von Zedtwitz, M. (2002) Organizational learning through post-project reviews in R \& D. $R \& D$ Management, 32(3), 255-268.

Wang, S. and Noe, R. (2010) Knowledge sharing: A review and directions for future research., Human Resource Management Review (20), 115-131

Weiser, M. and Morrison, J. (1998) Project Memory: Information Management for Project teams. Journal of Management Information Systems, 14(4), 149-167. 
Williams, T. (2004) Identifying the hard lessons from projects - easily. International Journal of Project Management, 22(4), 272-279. 